UDC: 007:528.93]:004.6

DOI: $10.1448 /$ gn. 2014.10

Typology: 1.04 Professional Article

\title{
Laboratory for development of open source geospatial technologies - role in education and research
}

\author{
Milan Kilibarda ${ }^{1 *}$, Branislav Bajat ${ }^{1}$, Nemanja Branisavljević ${ }^{1}$ \\ ${ }^{1}$ University of Belgrade, Faculty of Civil Engineering, Belgrade, Serbia
}

\begin{abstract}
International Cartographic CBOs (International Cartographic Association- ICA) in partnership with the Open Source Geospatial Foundation-OSGeo has started the initiative ICA-OSGeo Labs to promote and use open source technologies in education and research. For many years, the use and development of the open source software and technologies have been present in the field of research and education at the Faculty of Civil Engineering at the Department of Geodesy and Geoinformatics, University of Belgrade. Additionally, at the University of Belgrade, Faculty of Civil Engineering a laboratory called "Laboratory for development of the open source geospatial technologies - OSGL" has recently been established. This paper presents the current experience of the lab members in using the open source software in geoinformatics, research and education as well as the perspectives and future activities of the newly formed laboratory.
\end{abstract}

Keywords: ICA-OSGeo Labs, open source, cartography, GIS, education 


\section{Introduction}

In September 2011, Open Source Geospatial Foundation-OSGeo ${ }^{l}$ has signed a memorandum of understanding with the International Cartographic CBOs (International Cartographic Association- ICA ${ }^{2}$ ) in order to promote the development of the GIS open source software and geospatial data. This resulted in an initiative called ICA-OSGeo $\mathrm{Labs}^{3}$ whose main objective is to encourage academic networking and networking with industry and government institutions that use free geospatial open source technologies (FOSS4G). In short, the initiative should provide access to the GIS software and materials for education and research to all interested in geoinformatics and the geospatial technologies.

One of the leading experts in application of geoinformatic technologies in the geospatial sciences, Professor Helena Mitasova from North Carolina State University in an interview with the Directions Magazine in March of 2014. defined causes for the existence of this initiative:

- A number of universities and educational institutions in developing countries offer very little training courses in the field of the geoinformation technologies and GIS (Geographic Information Science and Technology-GIST) due to the high cost of the commercial software.

- FOSS4G and the educational materials are freely available and instantly provide the required materials to the educational institutions in order to develop GIST programs according to local needs and requirements.

- GIST programs at most universities including Europe and the United States are based on the commercial software and this is why the network of laboratories that will promote the open source software will expand the capabilities and flexibility of the GIST study courses.

- FOSS4G is free software in terms of price, utilization and modification and is easy to use for both teachers and students.

- In addition, for FOSS4G there exists a welldeveloped infrastructure for the promotion and distribution of the training materials.

- Since the access of the source code and its modification that is usually required is in scientific research is not possible when using commercial software, the FOSS4G will provide the additional.

- The initiative aims to encourage the efforts of enthusiasts to strengthen the FOSS4G community, especially for the educational purposes.

Even before the official acceptance of this initiative, the Department of Geodesy and Geoinformatics in the Faculty of Civil Engineering, University of Belgrade was actively using the open source software in education of geodetic engineers at the undergraduate, graduate and $\mathrm{PhD}$ studies. A large number of bachelor, master and doctoral thesis was created using the open source software. Additionally, a significant number of scientific papers has also been published using open source software $[1-4 ; 7 ; 10-15]$.

Department of Geodesy and Geoinformatics organized numerous workshops and conferences on the use of software in geospatial analysis that is based on the open source technologies. Additionally, several local workshops in September 2011 has been organized and one international conference entitled " $R$ + OSGeo in Higher Education (Belgrade, RS)" ${ }^{4}$. In June of 2014 the international workshop and the conference entitled "Spatial and spatio-temporal modelling of meteorological and climatic variables using Open Source Software $(R+O S G e o)^{\prime}{ }^{5}$ will be organized.

The development of the Laboratory for development of open source geospatial technologies OSGL at the Department of Geodesy and Geoinformatics seemed like the logical next step in the process of promotion and cultivation of a noncommercial approach to the improvement of teaching and research at the University.

\section{Geospatial technologies in teaching and research}

In the department of Geodesy and Geoinformatics, the open source software has been actively applied in cartography and geoinformatics for a long time. Desktop GIS software used in both teaching and research were mostly SAGA-GIS ${ }^{6}$ and QGIS $^{7}$. These software packages offer rich functionality for working with vector and raster data, as well as access to Web services, cartographic design

\footnotetext{
${ }^{4}$ http://geostat-course.org/R_OSGeo_in_Education_Belgrade

5 http://dailymeteo.org/2014

${ }^{6}$ http://www.saga-gis.org/en/index.html

http://www.qgis.org/en/site/
} 
of digital maps, process modelling using graphical modeller or Python ${ }^{8}$ language. Additionally, with the SEXTANTE ${ }^{9}$ modeller it is possible to combine the $\mathrm{R}$ programming language together with SAGA-GIS and QGIS features, as well as the GRASS GIS ${ }^{10}$, GDAL/OGR ${ }^{11}$, Orfeo Toolbox ${ }^{12}$ functions, and others.

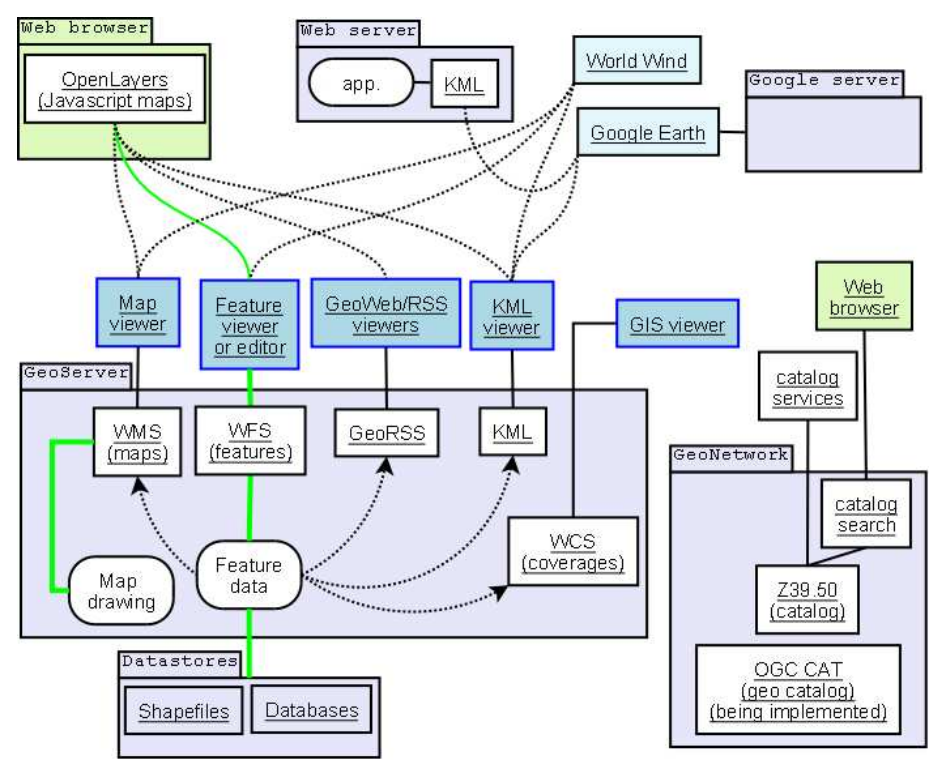

Figure 1. Link between the client and server open source applications with OGC standard services [17]

On the postgraduate studies beside to desktop GIS application, Web GIS and Web mapping applications were extensively used - server applications, like Geoserver ${ }^{13}$, Mapserver ${ }^{14}$ and client applications like OpenLayers ${ }^{15}$, GeoExt ${ }^{16}$ and others, to produce the good quality cartographic server-client applications.

Since the open source software are particularly attractive for the development of Web GIS and Web mapping applications, large number of projects, BSc, MSc and Phd thesis were based on the Web mapping applications following web standards, which is graphically shown in Figure 1.

As a part of the educational and the research process, the Laboratory for development of open source geospatial technologies will be partly focused on the bachelor, master and doctoral thesis, based on the open source geospatial technologies, developed at the Department of Geodesy and Geoinformatics, at the Faculty of Civil Engineering. The source code written during BSc and MSc thesis development and the adequate documentation will be presented on the laboratory's web site and therefore will be available to the community for further development and use. In that way the laboratory will contribute to the open source community and will provide additional material sources for further education and research.

\section{Examples}

Master thesis of the candidate Vuk Jevtic titled "Design of cartographic web client using the CORINE database for Serbia" was entirely based on the open source technologies [9]. The aim of this postgraduate research is to design a Web cartographic client and its communication to the server (in this case, GeoServer), as well as with customers. One of the most popular client-oriented set of tools and library OpenLayers and GeoExplorer ${ }^{17}$ application (Figure 2) were used for the design purposes of this project/thesis.

Master thesis "Styling of web maps in open source software" of the candidate Milan Božić, describes cartographic design of spatial data using the open source web software GeoServer and SLD (Styled Layer Descriptor ${ }^{18}$ ) standards (see Figure 3) [5].

Master thesis of the candidate Miljana Ivković focuses on the integration of large data sets in virtual globe Google Earth ${ }^{19}$ [8]. For the reasonable amount of data Google Earth seems like an acceptable solution (Figure 4), since the small amounts of data can be easily published on a remote server and efficiently retrieved by the client. Additional solutions are required for the large datasets, usually in the form of the standard web mapping clients, such as Open Layers.

Climatic geoportal development based on the open-source technologies was the subject of a master's thesis of Stevan Milić [16]. In this thesis, in addition to the geospatial Web technology, PostgreSQLPostGIS $^{20}$ software for geospatial database is used to enhance the service with the relational database.

\footnotetext{
${ }^{8}$ https://www.python.org/

${ }^{9} \mathrm{http}: / / \mathrm{www}$. sextantegis.com/

${ }^{10} \mathrm{http}: / / g r a s s . o s g e o . o r g /$

${ }^{11} \mathrm{http}: / /$ www.gdal.org/

$12 \mathrm{http}$ ://orfeo-toolbox.org/otb/

${ }^{13} \mathrm{http}$ //geoserver.org/display/GEOS/Welcome

${ }^{14} \mathrm{http}: / /$ mapserver.org/

${ }^{15} \mathrm{http}: / /$ openlayers.org/

${ }^{16} \mathrm{http}: / /$ geoext.org/
}

\footnotetext{
${ }^{17} \mathrm{http} / / /$ suite.opengeo.org/docs/latest/geoexplorer/

${ }^{18} \mathrm{http} / / /$ www.opengeospatial.org/standards/sld

${ }^{19} \mathrm{http}: / /$ www.google.com/earth/

${ }^{20} \mathrm{http}: / /$ postgis.net/
} 


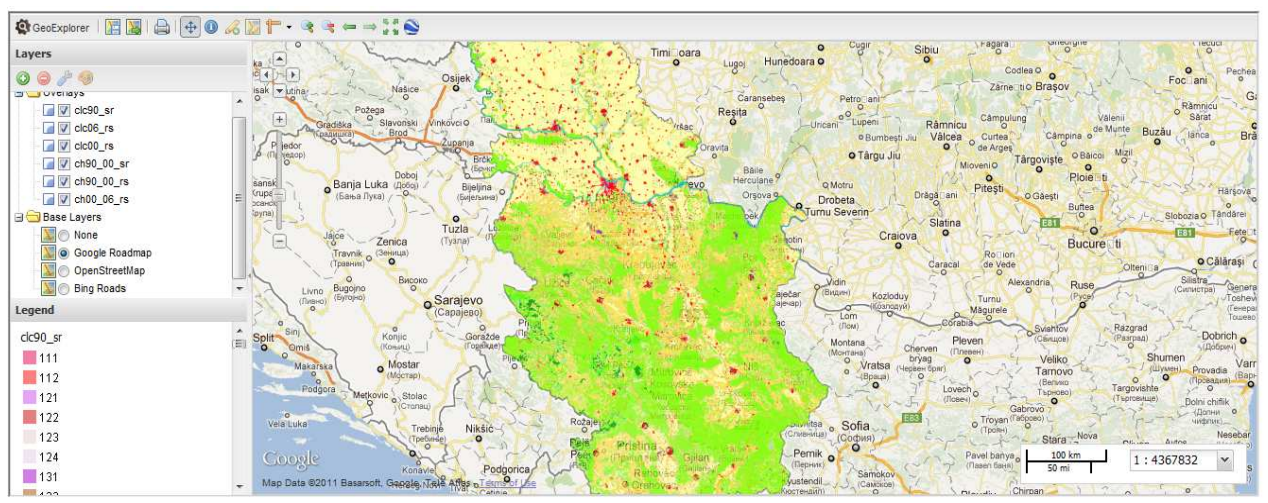

Figure 2. Client application CORINE map of the soil surface (source: Vuk Jevtić " Design of cartographic web client using the CORINE database for Serbia ", master thesis, 2011)

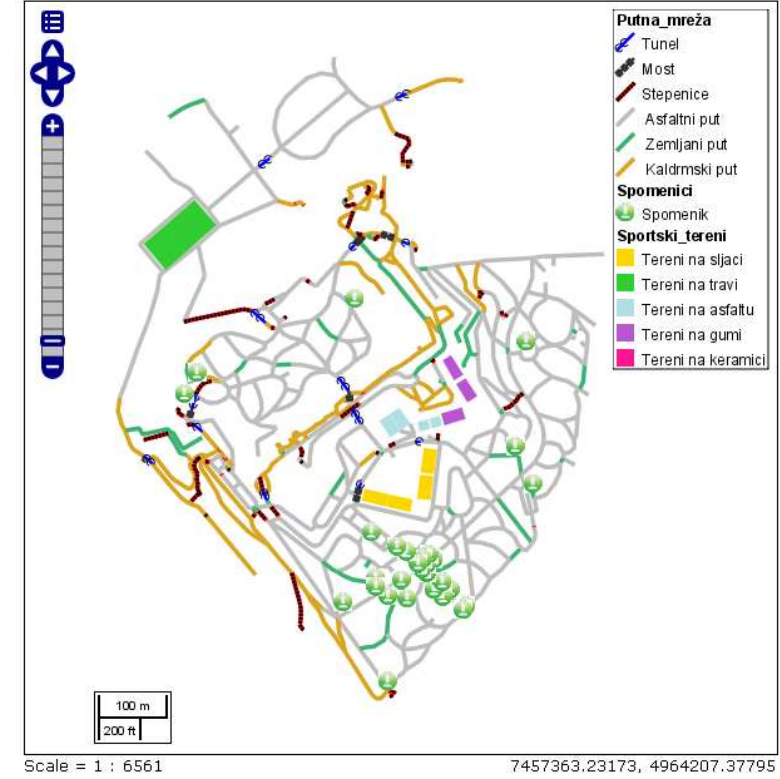

Figure 3. Touristic web map of Kalemegdan fortress [5]

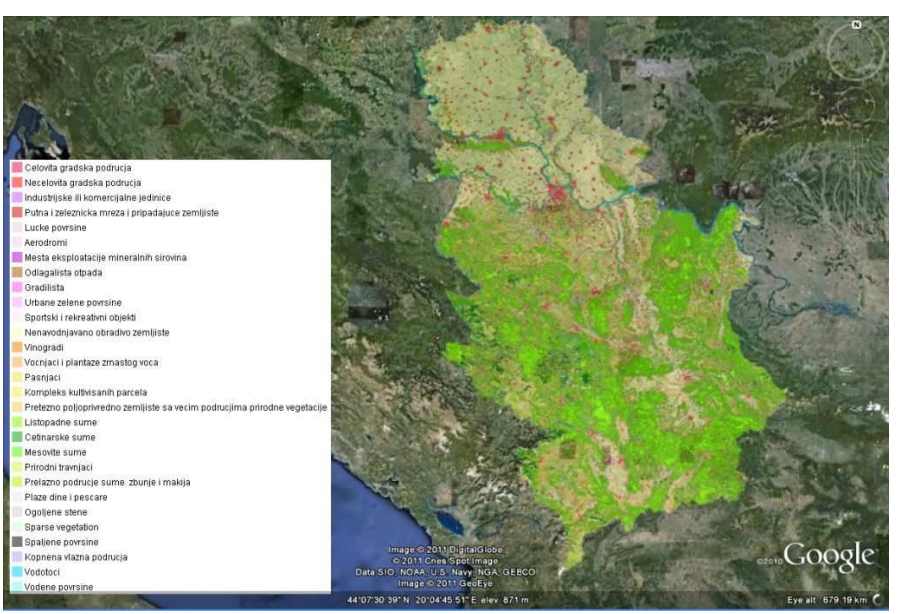

Figure 4. CORINE map of the soil surface in Google Earth, virtual globe [8]
As a part of his research, Milan Kilibarda has developed and continues to upgrade $\mathrm{R}$ software package plotGoogleMaps ${ }^{21}$ as the open-source software package. Detailed description of the functionality of this $\mathrm{R}$ package can be found in [10]. When using this package, mapping of vector, raster, and spatial-temporal data in the form of interactive Web maps, using the plotGoogleMaps package becomes a simple process. When using plotGoogleMaps package in $\mathrm{R}$ programming environment, it is possible to create a web map based on Google Maps API ${ }^{22}$ technology without knowledge of the internet technologies, or any JavaScript or HTML programming. The application of this package is verified through visualization geostatistical analysis, statistical demographic data, geological data surveying, mapping, risk mapping and surveying networks with error ellipses (Figure 5) [10]. Scripts and data for testing can be downloaded from the web site of the author ${ }^{23}$.

The main contribution of the $\mathrm{R}$ package plotGoogleMaps is based on a modern approach to the presentation and analysis of the results of numerous scientific papers from the Department of Geodesy and Geoinformatics. Application plotGoogleMaps packages in the geological survey in the area of New Belgrade is described in [12], the application of the package for visualizing the floodplain area and the risk of landslides is given in the paper [3], visualization of the valuation of real estate in the city of Belgrade is given in paper [4]. Visualization of the analysis of rainfall trends in Serbia in the period from 1961 to $2009^{24}$ is given in [15], visualization of

\footnotetext{
${ }^{21}$ http://cran.r-

project.org/web/packages/plotGoogleMaps/index.html

${ }^{22} \mathrm{https} / / /$ developers.google.com/maps/

${ }^{23} \mathrm{http}: / /$ www.grf.bg.ac.rs/ bajat/geomatica_script_and_data.zip

${ }^{24} \mathrm{http} / / /$ grf.bg.ac.rs/ bajat/Trends.htm
} 
uncertainty (the results of cross-validation) of spatiotemporal geostatistical prediction of daily temperatures at a resolution $1 \mathrm{~km}^{25}$ above the Earth's surface is given in [13].

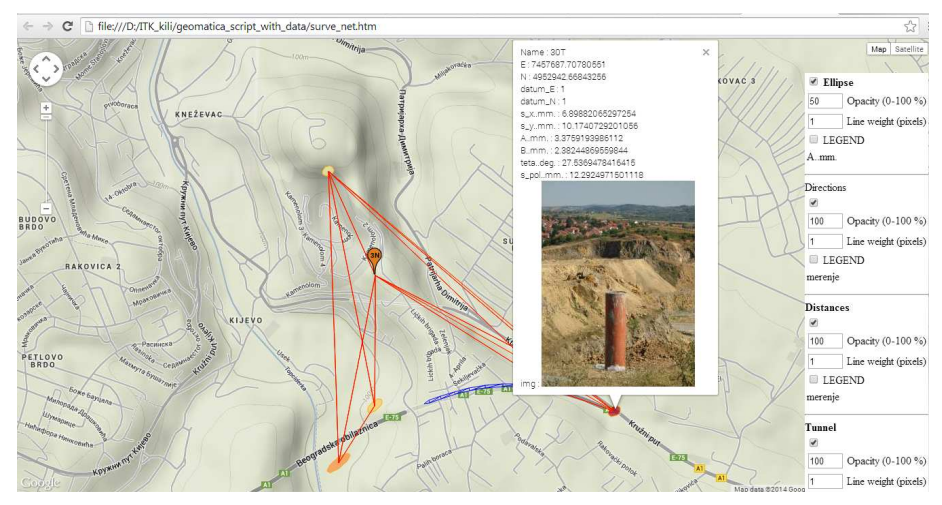

Figure 5. Least square adjustment of geodetic network in plotGoogleMaps software package.

Space-time interpolation of the daily temperatures above the Earth's surface [13] is implemented in the $\mathrm{R}$ software package "meteo" 26 , that is currently in the demo version. For the prediction of the medium, minimum and maximum temperature regression kriging was used with auxiliary predictors: MODIS LST 8-day images, topographic layers (DEM and TWI) and geometrical temperature trend. This also applies to prediction model related to the 2011 year, but the same methodology could be applied from 2001 until now (since the MODIS images are available from from that period).

\section{Discussion and conclusion}

Through a connection with the existing network ICA OSGeo Network laboratories ${ }^{27}$ as well as through the work of the Association Geoinformation Lab Europe (AGILE) the further development of $O S G L$ will go on in the following directions:

- Further improvement of a curriculum in the field of geoinformatics at the Department of Geodesy and Geoinformatics as well as other departments of the Faculty of Civil engineering and other faculties at the University of Belgrade.

- Participation in international research and scientific projects in collaboration with the laboratories of the similar profile.

- Implementation and promotion of the open

\footnotetext{
${ }^{25} \mathrm{http} / / /$ dailymeteo.org/node/3

${ }^{26} \mathrm{https}$ ://r-forge.r-project.org/projects/meteo/

${ }^{27} \mathrm{http}: / / \mathrm{www} . \mathrm{geoforall} . \mathrm{org} /$ locations/
}

source technologies in the domestic and international industry and the economy.

- Membership laboratories in aforementioned associations will make the work and the results of the Department of Geodesy and Geoinformatics even more visible in the competitive market of the geoinformation technologies.

The development of the geoinformation technologies that marked the last decades of the last century and the current course of this century is strongly linked to the results of the activities at universities around the world [6]. The involvement of the large software companies in the market and commercialization of the software solutions did not affect the leading role in the area of improving the geoinformation technologies, played by the developing groups at the universities. Academic population still holds the key role in the development of the new ideas in the geographic information sector through the implementation of the open source software solutions.

Therefore, development and popularization of the open source solutions within the teaching and research process and their promotion and implementation in the various businesses whose activities are related to geospatial technologies, will be a target activities that will take place within a Laboratory for development of open source geospatial technologies.

\section{Acknowledgement}

This study is fully supported by the research projects TR 36035: Spatial, ecological, energy, and social aspects of settlements' development and climate changes interrelationships, funded by the Ministry of Education and Science of the Republic of Serbia.

\section{References}

[1] Bajat B., Hengl T., Kilibarda M., Krunić N.: Mapping population change index in Southern Serbia (1961-2027) as a function of environmental factors. Computers, Environment and Urban Systems, Vol. 35, No. 1, pp. 3544, 2011.

[2] Bajat B., Krunić N., Kilibarda M.: Dasymetric mapping of spatial distribution of population in Timok Region, In Proceedings of International conference Professional practice and education in geodesy and related fields, Klavodo-Djerdap, Serbia, 2011.

[3] Bajat B., Krunić N., Bojović M., Kilibarda M.,

Kovacević Z.: Population vulnerability assessment in hazard risk management: A dasymetric mapping approach, 2nd Project Workshop on Risk Identification and Land-Use 
Planning for Disaster Mitigation of Landslides and Floods, Rijeka, Croatia, 15-17 December 201, pp.167-170, 2011. [4] Bajat B., Kilibarda M., Pejović M., Samardžić-Petrović M.: Spatial Hedonic Modelling of Dwelling Location Prices Using Auxiliary Maps, CD Proceedings of RSAI 9th Congress, Timisoara, Romania, 9-12 May 2012, 2012. [5] Božić M.: ,Stilizacija Web karata u Open Source softverima“", master thesis. Belgrade: University of Belgrade, Faculty of Civil Engineering, 2011.

[6] Burrough P., McDonnell R.: „Principi geografskih informacionih sistema“", Belgrade: University of Belgrade, Faculty of Civil Engineering. 2006.

[7] Dragović S., Ćujić M., Slavković-Beskoski L., Gajić B., Bajat B., Kilibarda M., Onjia A.: ,Trace element distribution in surface soils from a coal burning power production area: A case study from the largest power plant site in Serbia“, Catena 104, pp. 288-296, 2013

[8] Ivković M.: „Integracija velikog seta podataka u virtuelni globus Google Earth“, master thesis. Belgrade: University of Belgrade, Faculty of Civil Engineering, 2011.

[9] Jevtić V.: „Dizajn Web kartografskog klijenta na primeru CORINE baze podataka za Srbiju“"master thesis. Belgrade: University of Belgrade, Faculty of Civil Engineering, 2011.

[10] Kilibarda M., Bajat B.: PlotGoogleMaps: The $r$ based web-mapping tool for thematic spatial data. Geomatica, Vol. 66, No. 1, pp. 37-49, 2012

[11] Kilibarda M., Pejović M.: Application of open source/free software ( $R+$ Google Earth) in designing $2 D$ geodetic control network. In Proceedings of International scientific conference and 14th meeting of Serbian Surveyors Professional practice and education in geodesy and related fields, pp. 24-26, 2011

[12] Kilibarda M., Radić Z., Bajat B.: Plotgooglemaps - A Simple Solution for Geological Survey Web Mapping. In Proceedings of MAEGS-17 Geology in Digital Age, Belgrade, Serbia, 14th-16th September 2011, 2011. [13] Kilibarda M., Hengl T., Heuvelink G., Graeler B., Pebesma E., Percec Tadić M., Bajat B.: Spatio-temporal interpolation of daily temperatures for global land areas at $1 \mathrm{~km}$ resolution. Journal of Geophysical Research:

Atmospheres, 2014.

[14] Krunić N., Bajat B., Kilibarda M., Tosić D.: Modelling the spatial distribution of Vojvodina's population by using dasymetric method. Spatium, No. 24, pp. 45-50, 2011.

[15] Luković J., Bajat B., Blagojević D., Kilibarda M.: Spatial pattern of recent rainfall trends in Serbia (19612009), Regional Environmental Change, DOI:

10.1007/s10113-013-0459-x., 2013.

[16] Milić S.: „Izrada geoportala na osnovu prostornih klimatskih podataka“",master thesis. Belgrade: University of Belgrade, Faculty of Civil Engineering, 2011. [17] http://en.wikipedia.org/wiki/

Open_Geospatial_Consortium, accessed in 2014. 